Int. J. Dev. Biol. 49: 773-780 (2005)

doi: $10.1387 / \mathrm{ijdb} .051995 \mathrm{vq}$

\title{
Regulated RNA processing in the control of Arabidopsis flowering
}

\author{
VICTOR QUESADA ${ }^{1}$, CAROLINE DEAN ${ }^{2}$ and GORDON G. SIMPSON*3,4 \\ ${ }^{1}$ División de Genética and Instituto de Bioingeniería, Universidad Miguel Hernández, Campus de Elche, Elche, Spain, ${ }^{2}$ Department of Cell \& \\ Developmental Biology, John Innes Centre, Norwich, U.K, ${ }^{3}$ Dundee University Plant Research Unit at SCRI, Invergowrie, Dundee, U.K. and \\ ${ }^{4}$ Gene Expression Programme, Scottish Crop Research Institute, Invergowrie, Dundee, UK.
}

\begin{abstract}
Flowering time is controlled in order to ensure reproductive success. Molecular genetic analyses in Arabidopsis thaliana have identified many genes regulating this developmental switch. One group of factors which promote flowering do so by down-regulating the expression of the MADS-box floral repressor, FLC. RNA processing appears to play an important role in this regulation as genes within this group encode RNA binding proteins (FCA, FPA and FLK) and an mRNA 3' end processing factor (FY). FCA promotes flowering and negatively autoregulates its own expression post-transcriptionally through a mechanism that involves alternative polyadenylation. FCA physically interacts with FY and this interaction is required for the function FY performs in flowering control and in FCA autoregulation. Potential similarities are emerging in the molecular mechanisms controlling FLC expression and those controlling the floral homeotic gene, AGAMOUS. In addition, microRNAs have been shown to regulate plant developmental processes including the timing to flower. Together, these new data indicate that post-transcriptional regulation of gene expression plays an important role in regulating the floral transition.
\end{abstract}

KEY WORDS: Arabidopsis thaliana, flowering time, RNA processing, RNA-binding protein, miRNA

\section{Introduction}

Flowering time control is a complex process that involves the integration of responses to multiple environmental stimuli and endogenous signals. This complexity ensures that flowering occurs in conditions favourable for reproductive success. The use of Arabidopsis thaliana as a model system has helped define the mechanisms that control flowering. The molecular genetic characterization of $A$. thaliana mutants defective in flowering time control has led to the identification of many genes involved in this process. These genes comprise genetically separable pathways that quantitatively control the transition to flowering. The role of these pathways can be classified as promoting, repressing and enabling flowering or resetting the vegetative state (Boss et al., 2004; Fig. 1). Distinct pathways promote flowering in response to day-length, the phytohormone gibberellic acid, changes in light quality and ambient temperature. These pathways converge on the activation of an overlapping set of genes known as "floral pathway integrators" (Simpson and Dean, 2002; Fig. 1). In turn, the products of these genes activate or up-regulate floral meristem identity genes required for flower formation such as APETALA1 (AP1), CAUL/FLOWER (CAL) and $\angle E A F Y$ ( $\angle F Y$; see Simpson and Dean,
2002) (Fig. 1). The up-regulation of floral pathway integrators is antagonized by the MADS box transcription factor, FLC, a key repressor of flowering in $A$. thaliana (Michaels and Amasino, 1999; Sheldon etal., 1999). Flowering is enabled by the autonomous and vernalization response pathways which prevent the accumulation of FLC mRNA (Fig. 1). Vernalization is the acceleration of flowering caused by a long period of cold and is considered to be an adaptation that ensures flowering occurs only after winter (reviewed in Amasino, 2004).

Progress in dissecting the molecular basis of flowering time control has been recently reviewed (Simpson and Dean, 2002; Mouradov et al., 2002; Boss et al., 2004; Henderson and Dean, 2004; Putterill et al., 2004; Simpson, 2004). It is clear that a range of regulatory processes are involved in flowering time control. These include transcriptional, post-transcriptional and post-translational control mechanisms. As $A$. thaliana flowering time is controlled in such a quantitative manner, it provides a genetically tractable system to study the molecular basis of regulated gene expression in higher plants. In this review we will focus on what is known of regulated RNA processing in flowering time control. The A. thaliana genome encodes 196 RNA Recognition Motif (RRM) -type RNA binding proteins, more than either Caenorhabditis

\footnotetext{
*Address correspondence to: Dr. Gordon G. Simpson. Dundee University Plant Research Unit at SCRI, Invergowrie, Dundee,DD2 5DA, UK. Fax: +44-1382-562-246. e-mail: g.g.simpson@dundee.ac.uk
} 
elegans or Drosophila melanogaster (Lorkovic and Barta, 2002). Around half of these RNA binding proteins are novel and specific to plants, indicating that they function in plant-specific processes. The only two plant-specific RRM-containing proteins of known function, FCA and FPA, are proteins that promote flowering. The $A$. thaliana genome also encodes $26 \mathrm{~K}$-Homology $(\mathrm{KH})$ domain RNA binding proteins. The function of only two of these, HUA ENHANCER 4 (HEN4) and FLK has been established and FLK also promotes flowering (Lim et al., 2004). In addition to RNA processing mediated by RNA binding proteins, the recent functional characterisation of $A$. thaliana microRNAs (miRNAs) has revealed that some are involved in flowering time control. Here, we review our current understanding of regulated gene expression mediated by RNA processing proteins and miRNAs in flowering time control.

\section{The regulation of $F L C$ expression is complex and involves multiple RNA processing factors}

The RNA binding proteins, FCA, FPA and FLK all promote flowering by preventing the accumulation of mRNA encoding the floral repressor $F L C$. The regulation of $F L C$ expression is complex. In order to understand how RNA processing regulates flowering, it is first necessary to review the mechanisms by which FLC expression is controlled. In this way, we identify potential targets of RNAmediated regulation and set the context in which these RNA binding proteins function.

The study of natural variation in flowering time in $A$. thaliana showed that most vernalization-requiring winter annual accessions of $A$. thaliana flower late in the absence of vernalization because of the presence of elevated levels of FLC mRNA promoted by $F R I G I D A(F R /)$. In contrast, most rapid cycling accessions analysed flower earlier in the absence of vernalization as they carry loss of function fri alleles (Johanson etal., 2000). The regulation of $F L C$ by $F R /$ specifically requires $F R / G I D A L I K E 1$ and 2 (FRL1 and FRL2) (Michaels et al., 2004). The mechanism by which $\mathrm{FRI}$ increases FLC expression has not been determined. However, it has recently been shown that this is associated with enhanced histone 3 trimethylation at Lysine (Lys) 4 in FLC chromatin (He et al., 2004).

A collection of factors are required for FLC mRNA accumulation. Prominent among these are $A$. thaliana proteins related to the Paf1 complex of yeast: VERNALIZATION INDEPENDENCE 4 (VIP4; Zhang and van Nocker, 2002), VIP5, VIP6/ EARLY FLOWERING 8 (ELF8) (Oh et al., 2004; He et al., 2004) and ELF7 (He et al., 2004) (see Fig. 1) with homology to budding yeast Leo1, Rtf1, Ctr9 and Paf1 proteins respectively. The yeast Paf1 complex associates with RNA polymerase II transcribing a sub-set of genes and promotes trimethylation of histone $3(\mathrm{H} 3)$ on Lys4 (K4), a chromatin modification at the 5' end of genes associated with active transcription (Santos-Rosa et al., 2002). These proteins are required for the same chromatin modification in the 5' region of $A$. thaliana FLC (He et al., 2004). Trimethylation of $\mathrm{H3}-\mathrm{K} 4$ in the 5' regions of genes is thought to promote gene expression by recruiting ISW1p, a yeast ATP-hydrolysing chromatin remodelling protein. PHOTOPERIOD-INDEPENDENT EARLY FLOWERING 1 (PIE1) is a candidate for a protein fulfilling this function in $A$. thaliana as it is related to ISW1 $p$ and loss-of-function pie 1 mutants have reduced levels of FLC mRNA (Noh and Amasino, 2003). In yeast, loss-of-function mutations in Paf1 complex components also results in RNA processing defects, such as shortened poly (A) tails on transcribed mRNAs (Mueller et al., 2004). This might be explained by changes in the phosphorylation status of the Cterminal domain (CTD) of the large subunit of RNA polymerase II that are found in these mutants which would compromise the association of RNA processing factors with the elongating polymerase. The Paf1 complex regulates the expression of a sub-set of $A$. thaliana genes that includes transcription factors, like $F L M$, that are related to FLC (He et al., 2004).

In addition to the Paf1 complex and PIE1, FLC expression depends on EARLY in SHORT DAYS 4 (ESD4) (Reeves et al., 2002) and EARLY FLOWERING 5 (ELF5) (Noh etal., 2004). ESD4 encodes a nuclear protein related to proteases that are specific for SMALL UBIQUITIN-RELATED MODIFIER (SUMO) (Murtas et al., 2003). ELF5 is similar to a WW domain containing nuclear Npw38binding protein, NpwBP. The mechanism by which ESD4 and ELF5 promote $F L C$ mRNA expression is not yet known.

While the Paf1 complex promotes FLC transcription, other factors required for $F L C$ mRNA accumulation may act posttranscriptionally, ABA HYPERSENSITIVE 1 ( $A B H 1$ ), which encodes the large subunit of the eukaryotic nuclear mRNA capbinding complex (CBP80; Hugovieux et al., 2002) and HUA2, a protein required for the efficient processing of $A G A M O U S$ premRNA intron 2 (Chen and Meyerowitz, 1999; Cheng et al., 2003) are both required for normal FLC expression (Bezerra et al., 2004; Doyle et al., 2005).

CBP80 binds the cap structure attached to the 5 ' end of the eukaryotic transcripts produced by RNA polymerase II. The expression of only a small sub-set of $A$. thaliana transcripts appear sensitive to loss of this cap-binding protein (Hugovieux et al., 2002), but the reason why $F L C$ should be one of them is unknown. The processing of first introns can be enhanced by exon bridging interactions between splicing factors and the cap-binding complex (Lewis et al., 1996). Some feature, possibly a weak 5' splice site or the large size of $F L C$ intron 1 may make its processing more dependent on the cap-binding complex. Another possibility is that $\mathrm{ABH} 1$ bound to $F L C$ mRNA modulates its interaction with $F L C$ regulators (such as the RNA binding proteins of the autonomous pathway). Alternatively, the effect might be indirect and $A B H 1$ may affect the activity of genes required for $F L C$ expression (Bezerra et al., 2004).

The HUA2 protein sequence contains an RPR domain, a motif found in proteins that function in RNA metabolism and HUA2 affects $A G$ pre-mRNA processing in certain genetic backgrounds (Cheng et al., 2003). HUA2 is required for the accumulation of $F L C$ mRNA and other related MADS box transcription factors that are also repressors of flowering such as FLOWERING LOCUS $M$ (FLMIMAF1; Scortecci et al., 2001), MAF2 (Ratcliffe et al., 2003) and SHORT VEGETATIVE PHASE (SVP; Hartmann et al., 2000) which are also regulated by the Paf1 complex (Doyle et al., 2005).

The up-regulation of $F L C$ mRNA by $F R /$ in winter annual accessions of $A$. thaliana confers a so-called vernalization requirement. Down-regulation of $F L C$ expression is a basic feature of the $A$. thaliana vernalization response. The epigenetic maintenance of $F L C$ repression is mediated by chromatin modifications. Consistent with this, factors that modify chromatin at the $F L C$ locus are required for the vernalization response of $A$. thaliana (Gendall et al., 2001; Bastow et al., 2004; Sung and Amasino, 2004). Vernal- 
ization also apparently promotes the alternative processing of $A$. thaliana FLC pre-mRNA (Caicedo et al., 2004). Following 15 days vernalization treatment (growth at $4^{\circ} \mathrm{C}$ ), a short transcript is detected, the putative product of alternative splicing involving the use of unprecedented non-canonical splice donor and acceptor sites within intron 1 and 6 respectively (Caicedo et al., 2004). The functional significance of this transcript in the regulation of $F L C$ expression or activity remains to be determined.

The autonomous pathway prevents the accumulation of $F L C$ mRNA (Simpson, 2004). The autonomous pathway currently comprises seven recessive loss-of-function mutants: fca, fy, fpa, fve, fld, luminidependens (Id) (Koornneef et al., 1998) and flk (Lim et al., 2004). The genes disrupted in each of the known autonomous pathway mutants have been identified. $\angle D$ encodes a homeodomain containing protein (Lee et al., 1994). Such domains typically bind DNA, or more rarely, RNA (Dubnau and Strhul, 1996; RiveraPomar etal., 1996). Other genes of the autonomous pathway, FCA, $F P A$ and $F L K$, encode RNA binding proteins (Macknight et al., 1997; Schomburg et al., 2001; Lim et al., 2004), while FY is probably a polyadenylation factor (Simpson et al., 2003). FLD and FVE encode proteins that modify FLC chromatin. FLD is homologous to the human protein KIAA0601, a component of the histone deacetylase 1,2 (HDAC1/2) co-repressor complexes (He et al., 2003), while FVE is a WD repeat-protein and homolog of the mammalian Retinoblastoma Associated Protein46 (RbAp46) and $\mathrm{RbAp48}$ proteins (Ausin etal., 2004). FLD and FVE are required for histone deacetylation of chromatin at the FLC locus, but the RNA binding proteins of the autonomous pathway, FCA and FPA, are not ( $\mathrm{He}$ et al., 2003). It is well established in many systems that histone deacetylation is associated with repression of gene expression (Cress and Seto, 2000; Yang and Seto, 2003; Tian et al., 2005). The recently identified RELATIVE OF EARL Y FLOWERING 6 (REFG) gene, which encodes a Jumonji/zinc-finger-class transcription factor, could also be considered part of the autonomous pathway: loss-of-function ref6 mutants show elevated levels of $F L C$ mRNA, flower later than wild-type in long days (LDs) and short days (SDs) and this late flowering can be overcome by a vernalization treatment. ref6 mutants display hyperacetylation of histone $4(\mathrm{H} 4)$ in FLC (Noh et al., 2004b). Therefore, REF6, like $F L D$ and $F V E$, is required for histone deacetylation of chromatin at the $F L C$ locus.

The potency with which FLC acts as a floral repressor differs between $A$. thaliana accessions. The relatively weak activity of the Landsberg erecta (Ler) $F L C$ allele is caused by the insertion of a transposable element in FLC intron 1 (Gazzani et al., 2003; Michaels etal., 2003). Small interference RNAs (siRNAs) corresponding to the transposon accumulate in Ler and this correlates with an increase in histone 3 (H3) dimethylation on Lysine 9 (K9) within this intron (Liu et al., 2004). The late flowering mutant, hua enhancer 1-1 (hen1-1), shows an accumulation of $F L C$ mRNA and a reduction in the levels of $F L C$ intron 1 siRNAs and $\mathrm{H} 3-\mathrm{K} 9$ dimethylation. HEN1 is involved in siRNA metabolism (Xie et al., 2003) and is required for the accumulation of FLC intron 1 siRNAs (Liu et al., 2004). Therefore, HEN1 participates in the production of siRNAs homologous to FLC intron 1 which triggers dimethylation of $\mathrm{H} 3-\mathrm{K} 9$ within intron 1, leading to the silencing of $F L C$ expression. This discovery establishes a clear connection between post-transcriptional and chromatin modification mechanisms in the control of $F L C$ gene expression affecting $A$. thaliana flowering time control.
The regulation of $F L C$ expression therefore involves many factors, some that act directly to modify chromatin at the FLC locus and others that are involved in RNA processing. The RNA binding proteins must either regulate $F L C$ directly or antagonize

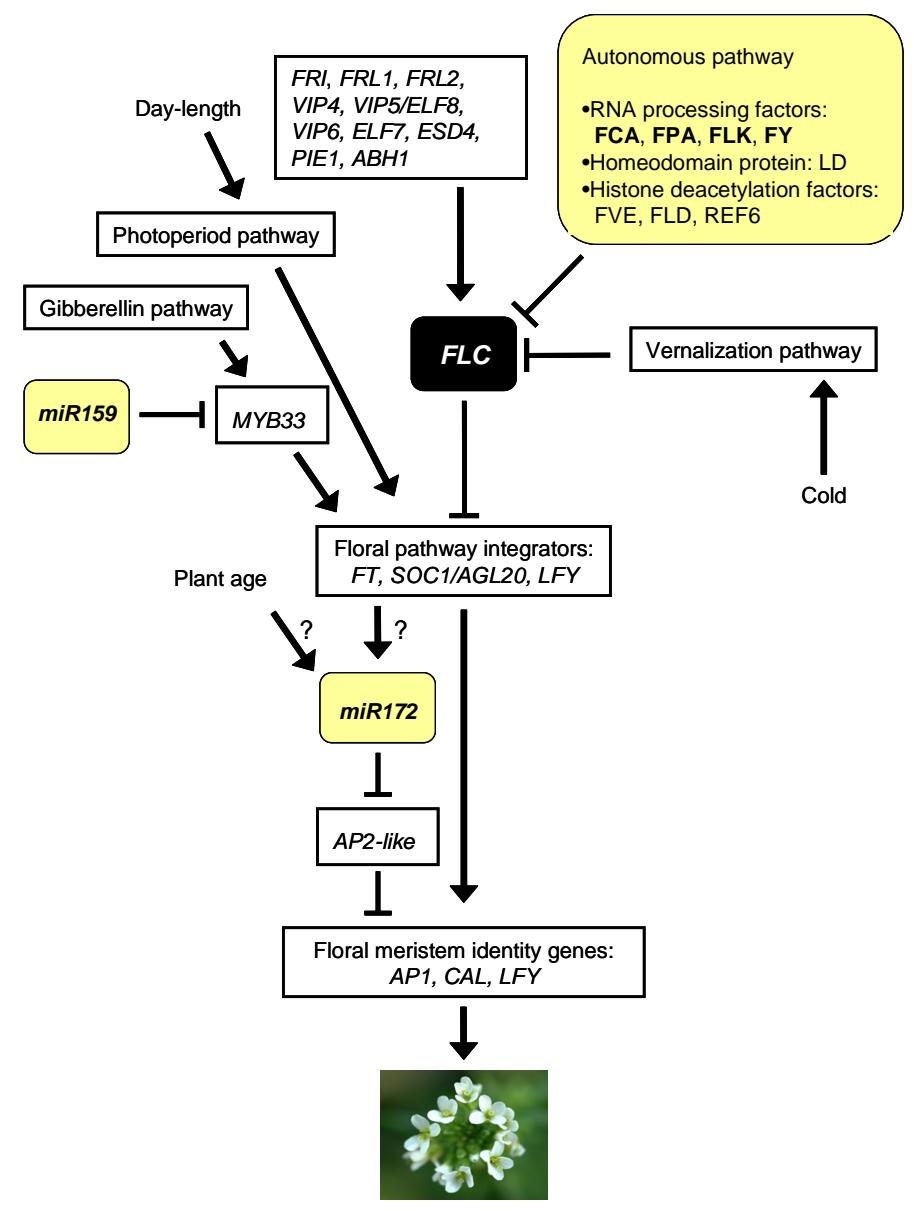

Fig. 1. Schematic representation of the principal pathways controlling flowering time in $\boldsymbol{A}$. thaliana. The photoperiod and gibberellin pathways promote the activity of the floral pathway integrator genes FT, SUPRESSOR OF THE OVEREXPRESSION OF CO1/AGAMOUS LIKE 20 (SOC1/AGL20) and LEAFY (LFY), whereas the MADS-box transcription factor FLC represses their activity. Up-regulation of FLC expression depends on FRIGIDA (FRI), FRI-like1 (FRL1) and 2 (FRL2), VERNALIZATION INDEPENDENCE 4 (VIP4), VIP5/EARLYFLOWERING 8 (ELF8), VIP6, ELF7, EARLY INSHORT DAYS 4 (ESD4), PHOTOPERIOD INSENSITIVE EARLY 1 (PIE1) and ABA HYPERSENSITIVE 1 (ABH1), while FLC mRNA expression is inhibited by the genes of the autonomous and vernalization pathways. In the autonomous pathway, FCA, FPA, FLK andFY (bold letters) encode RNA processing factors, $L D$ is a homeodomain containing protein and FVE, FLD and RELATIVE OF EARLY FLOWERING 6 (REF6) genes encode factors required for deacetylation of histones at the FLC locus. miRNAsmiR159 and miR172 repress and promote flowering time respectively by negatively regulating (post-transcriptionally) the expression of MYB33 (miR159) and AP2-like floral repressors ( miR172). The floral integrators activate the expression of a highly redundant set of genes that includes APETALA1 ( AP1), CAULIFLOWER (CAL) and LFY which are required for floral meristem identity. Question marks denote that there is a current lack of consensus in the literature regarding whethermiR172 expression is affected by plant age orCO and FT. Promoter and repressive activities are denoted by arrowheads and T-bars, respectively. 
the expression or activity of factors that promote $F L C$ expression.

\section{Post-transcriptional autoregulation of $F C A$ expression controls flowering time in $A$. thaliana}

FCA is perhaps the best characterized autonomous pathway component. FCA is a nuclear protein containing two RNA recognition motif (RRM)-type RNA-binding-domains and a WW protein interaction domain (Macknight, et al., 1997). The expression of $F C A$ is complex, since four different transcripts $(\alpha, \beta, \gamma$ and $\delta)$ are produced as a result of alternative splicing and alternative polyadenylation events that take place at two different sites in FCA premRNA. In transcript $\alpha$, all the introns are excised with the exception of intron 3 which is retained. Transcript $\beta$ results from premature cleavage and polyadenylation at a promoter-proximal poly $(A)$ (polyadenylation) site within intron 3 (Macknight, et al., 1997; Fig. 2). At $3.0 \mathrm{~kb}$, intron 3 is unusually long compared to most $A$. thaliana introns. The alternative processing of intron 3 and its large size has been conserved in other plant species (Macknight, et al., 2002). FCA transcripts, $\gamma$ and $\delta$, lack introns but are differentiated by an alternative splicing event around intron 13 that produces the $\delta$ transcript and results in a shift in the reading frame that introduces a premature termination codon (PTC) (Macknight, et al., 1997). The consequence of the alternative processing of the FCA premRNA is the formation of three transcripts $(\alpha, \beta$ and $\delta$ ) encoding truncated and inactive proteins at the expense of transcript $\gamma$, the only fully spliced transcript able to encode full-length active FCA protein (Macknight, et al., 2002; Fig. 2).

The alternative processing of $F C A$ pre-mRNA is regulated and a major regulator is FCA itself. FCA negatively regulates its own expression by ultimately promoting cleavage and polyadenylation at the promoter-proximal poly (A) site within intron 3 (Quesada et al., 2003; Fig. 2). This results in the formation of the truncated and inactive $\beta$ transcript limiting the formation of the fully spliced, fulllength and functional $F C A \gamma$ transcript (Fig. 2). This post-transcriptional regulation is developmentally controlled, restricting in a temporal and spatial manner the pattern of expression of functional FCA protein (Quesada et al., 2003). However, this negative feedback either does not take place, or is less effective in meristematic regions (Macknight et al., 2002; Quesada et al., 2003).

FCA autoregulation has a functional consequence on flowering time. The expression of $F C A$ from intronless transgenes, lacking the cis-element required for $F C A$ regulation results in precocious flowering (Quesada et al., 2003). FCA autoregulation therefore provides a mechanism to fine-tune the level of functional FCA protein and in turn, FLC mRNA accumulation and thereby controls flowering time.

\section{FCA interacts with the polyadenylation factor FY to control FCA expression and flowering time}

FCA contains a WW domain that is involved in protein-protein interactions (Sudol and Hunter, 2000). The FCA WW domain interacts with another protein of the autonomous pathway, FY (Fig. 2), a WD-repeat protein highly related to the Saccharomyces cerevisiae RNA 3'-end-processing factor, Pfs2p (polyadenylation factor 1 subunit 2; Ohnacker et al., 2000). Consistent with its association with the FCA WW domain and its similarity to Pfs $2 p, F Y$ is genetically required for the function FCA performs in promoting

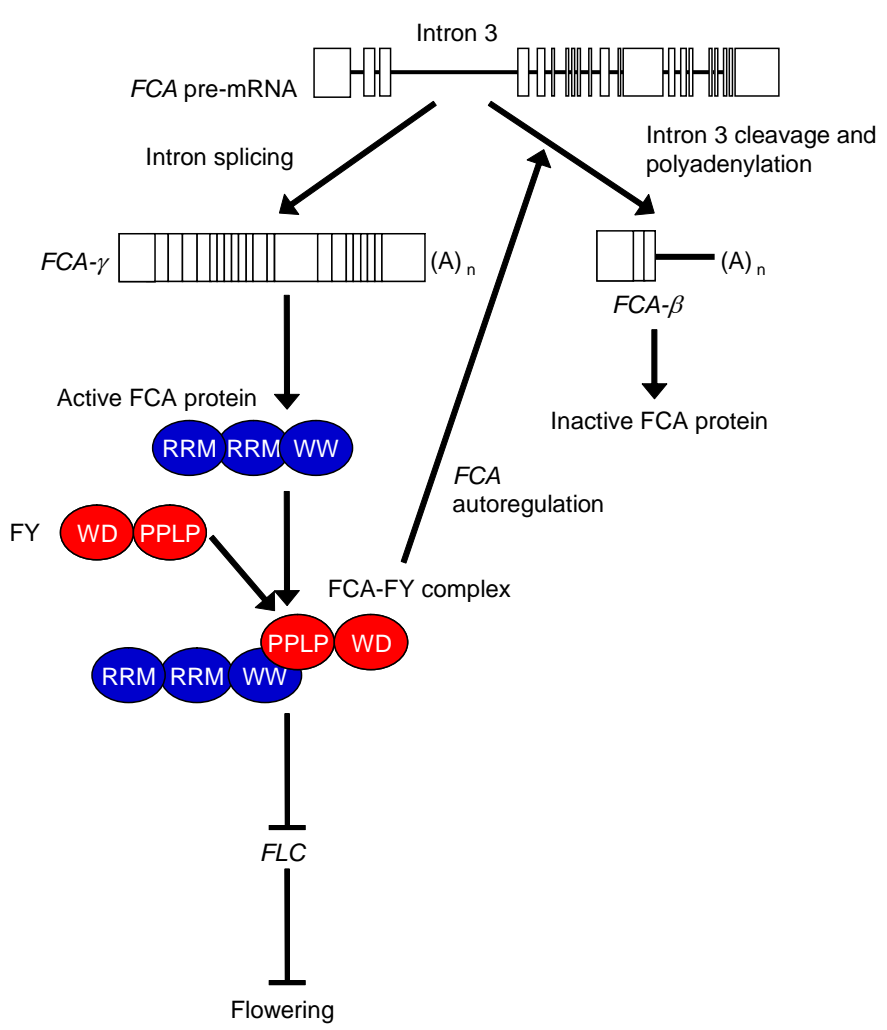

Fig. 2. FCA negative autoregulation and control of flowering time. Excision of all FCA pre-mRNA introns results in FCA transcript $\gamma$ which encodes a full-length and functional FCA protein. Through the WW domain FCA interacts with the PPLP motif in the C-terminal part of the $3^{\prime}$ end processing factor $F Y$. This may tether the $3^{\prime}$ end formation machinery to inhibit the expression of the floral repressor gene FLC. It is not yet known whether this is a direct or indirect effect. The FCA-FY complex also functions to promote premature cleavage and polyadenylation within FCA intron 3. This might be direct, through the binding of the FCA RNA recognition motifs (RRM) to sequences in FCA pre-mRNA intron 3. This produces the truncated transcript FCA- $\beta$ that encodes a non-functional FCA protein. This autoregulation mechanism sets the levels of functional FCA protein encoded by the FCA- $\gamma$ transcript preventing precocious flowering. Exons are represented as boxes and introns by lines.

flowering and for FCA autoregulation. First, the loss-of function fy mutation suppresses the early flowering phenotype of transgenic lines over-expressing FCA (Simpson et al., 2003). Second, $F Y$ is required for the selection of the promoter-proximal 3'-end in FCA pre-mRNA, since $f y$ and $f c a$ mutants display defects in 3' end formation, with a reduced use of the promoter-proximal poly $(A)$ site within intron 3 of $F C A$ pre-mRNA and a concomitant increase in the use of the promoter-distal poly $(A)$ site. Both autoregulation and flowering time functions of $F C A$ require an intact FCA WW protein interaction domain (Simpson et al., 2003).

The FCA-FY complex functions to actively promote proximal poly (A) site usage in FCA pre-mRNA rather than inhibiting 3' endformation at this site. This is consistent with the idea that FCA interacts with FY in order to tether the 3 '-end-processing machinery to a regulated 3'-end. While direct evidence for this model is currently lacking, FCA may be described as a regulator of 3' end formation and FY may be a component of the complex required for constitutive 3' end formation. An alternative possibility is that FY 
function has specialized for regulated 3' end formation. The composition of constitutive and regulatory 3' end cleavage and polyadenylation complexes may differ. The $\mathcal{S}$. cerevisiae genome only encodes a protein related to FY (Pfs2p). However, other eukaryotic genomes encode proteins related not only to FY but also to CstF50, a polyadenylation factor identified in metazoans, which was until recently considered to be the functional homologue of $\mathcal{S}$. cerevisiae, Pfs2p (Ohnacker et al., 2000). The determination of FY-like protein-function will probably require the characterization of the protein assemblies it associates with in multicellular eukaryotes. It is notable that work on the molecular basis of regulated gene expression involved in flowering time control can raise questions about the mechanisms of gene expression control in all eukaryotes.

The interaction of FCA and FY is required for their function in the autonomous pathway to prevent FLC mRNA accumulation (Fig. 2). An obvious possibility is that they promote alternative 3 ' end formation of $F L C$ pre-mRNA. However, there is currently no data to support this, nor even any evidence that they regulate $F L C$ directly. FCA and FY could regulate $F L C$ indirectly via one of the many factors that control $F L C$ expression.

\section{FPA and FLK are plant-specific RNA binding proteins that regulate flowering time}

FPA and FLK are also components of the autonomous pathway that promotes flowering in $A$. thaliana by repressing $F L C$ (Schomburg et al., 2001; Lim et al., 2004; Fig. 1). FPA is an RNAbinding protein that contains three RNA recognition motifs in the $\mathrm{N}$ terminal region (Schomburg et al., 2001) whereas FLK has three $\mathrm{KH}$ type RNA-binding domains (Lim et al., 2004). Mutations in FCA or FPA do not perturb expression of $F L K$ and the expression of $F C A$ and $F P A$ is normal in the flk mutant. This suggests that these components do not regulate the expression of each other within the autonomous pathway. Double mutant analysis suggested the existence of two epistatic groups in the autonomous pathway: one including FCA and $F Y$ and the other FPA and FVE (Koornneef, 1998) (no double mutant with flk has yet been reported). Taken together, this suggests that the RNA-binding proteins of the autonomous pathway function in parallel and control $F L C$ expression independently.

\section{ELF5}

The recently identified floral repressor $E L F 5$ might be involved in RNA metabolism (Noh et al., 2004a) based on sequence similarity with a nuclear human protein (NpwBP) proposed to function in RNA processing (Komuro et al., 1999). If this is confirmed, it would extend the involvement of RNA processing factors in flowering time control beyond the autonomous pathway.

\section{Similarities between $F L C$ and $A G$ regulation}

There are some parallels between the regulation of $F L C$ expression and the floral homeotic gene $A G A M O U S(A G)$ that may provide clues about how the RNA processing proteins of the autonomous pathway (FCA, FPA, FLK and FY) function. FLC and $A G$ encode MADS-box transcription factors involved in different aspects of plant development. $A G$ is a C-class gene that specifies the identities of carpels and stamens and also controls determinacy of the floral meristem (Yanofsky et al., 1990). Both genes contain unusually long introns that harbour important $c i s$ regulatory sequences [intron 1 of $3.5 \mathrm{~kb}$ and intron 2 of $3.0 \mathrm{~kb}$ in length in $F L C$ and $A G$, respectively (Sheldon et al., 2002; Hong et al., 2003)]. In addition, both genes appear to be regulated epigenetically (Goodrich etal., 1997; He etal., 2003; Ausin etal., 2004) and by proteins involved in RNA metabolism (Macknight, et al., 1997; Li et al., 2001; Schomburg et al., 2001; Western et al., 2002; Cheng et al., 2003; Simpson et al., 2003; Lim et al., 2004). HUA1, HUA2, HUA ENHANCER2 (HEN2) and HEN4 are required for the normal processing of $A G$ pre-mRNA. HUA1 has a CCCH-type zinc finger, while HEN4 has a KH-domain (Cheng etal., 2003). HUA2 shares homology with metazoan RNA-processing proteins (Chen and Meyerowitz, 1999) and HEN2 is a DExH RNA helicase similar to the yeast Dob1 protein, a component of the nuclear exosome involved in the production of ribosomal RNAs and in pre-mRNA degradation (Western et al., 2002). The analysis of $A G$ expression in the loss-of-function triple mutants hua 1 hua2 hen2 and hual hen2 hen4 showed that processing of $A G$ pre-mRNA is compromised: less mature and functional $A G \mathrm{mRNA}$ and more alternative and longer RNA species accumulates in the triple mutants (Cheng et al., 2003). The two longer $A G$ RNA transcripts are nonfunctional by-products resulting from alternative polyadenylation events within the large intron 2. Therefore, the normal function of HUA1, HUA2, HEN2 and HEN4 proteins would be to promote splicing of intron 2 by repressing the use of the poly $(A)$ sites within intron 2, or alternatively, facilitating the removal of this intron. HUA1 and HEN4 proteins physically interact and HUA1 directly binds $A G$ RNA in vitro, suggesting that this regulation might be carried out directly by the HUA1-HEN4 complex (Cheng et al., 2003).

This mechanism of $A G$ expression control, involving competition between splicing and premature cleavage and polyadenylation of a large intron, is very similar to the autoregulation of FCA. While FCAFY ultimately actively promotes premature polyadenylation and thus represses active $F C A$ expression, in the case of $A G$, HUA1, HUA2, $\mathrm{HEN} 2$ and HEN4 either facilitate splicing of and/or inhibit premature cleavage and polyadenylation within intron 2 and thus promote active $A G$ expression. The apparent similarities between $A G$ and $F C A$ regulation raises the question of whether FCA and FY control FLC RNA 3' end formation in a similar way by promoting premature polyadenylation within the unusually large $F L C$ intron 1 . However, as previously mentioned, no alternatively polyadenylated transcripts of the $F L C$ gene have been detected in $A$. thaliana. This may be due to the instability of these transcripts or because $F L C$ is not a direct target of FCA-FY.

The fact that HUA2 is required both for the expression of $F L C$ and $A G$ at first appears to underline similarities between $F L C$ and $A G$ regulation. However, this may not necessarily be the case. The effects of hua2 mutations on $A G$ are dependent on hua1 mutations (Cheng et al., 2003). However, hual does not enhance the effects that hua2 has on flowering time (Doyle etal., 2005). Therefore, HUA2 may regulate $F L C$ and $A G$ by different mechanisms.

\section{Flowering time and miRNAs}

miRNAs have emerged as important regulators of developmental processes in a range of multi-cellular organisms. miRNAs are small non-coding regulatory RNAs, about 21 nucleotides in length, produced from the processing of longer precursor transcripts. 
Plant miRNAs identified to date display near-complete matches with a complementary sequence in their target mRNAs and this often produces the cleavage of the mRNA at this site. In contrast these complementarities are more limited in animals and miRNAs seem to act by repressing translation of the target messages (Bartel, 2004). Nevertheless, there are exceptions, since despite strong complementarity some plant miRNAs function by inhibiting translation (Aukerman and Sakai, 2003; Chen, 2003) as well as through promoting cleavage of target mRNAs (Kasschau et al., 2003; Schwab et al., 2005) and some animal miRNAs direct the cleavage of their target mRNAs (Yekta et al., 2004).

At least $92 A$. thaliana miRNAs have been described, with most targeting mRNAs coding for transcription factors involved in different developmental processes (Dugas and Bartel, 2004). The biological function of several $A$. thaliana miRNAs has been established (Rhoades et al., 2002; Emery et al., 2003; Palatnik et al., 2003). Three $A$. thaliana miRNAs, miR172, miR159 and miR156 are known to be involved in the regulation of flowering time.

The $A$. thaliana genome encodes four precursors of mir172: miR172a-1, miR172a-2, miR172b and mir172c. mir172 exhibits complementarity with the floral meristem and floral organ identity gene, $A P E T A L A 2$ ( $A P 2$ ) and a group of genes related to $A P 2$. This group includes TARGETOFEAT1 (TOE1), TOE2, SCHLAFMUTZE (SMZ), SCHNARCHZAPFEN (SNZ) and At5g67190. TOE1, TOE2, $S M Z$ and $S N Z$ are all repressors of $A$. thaliana flowering (Aukerman and Sakai, 2003; Schmid et al., 2003). The assignment of these repressors to particular flowering time pathways is currently unclear. Microarray analysis revealed that all four were down-regulated upon flowering and that this down-regulation was dependent on FT and CONSTANS (CO), indicating that they were repressors ultimately targeted by the photoperiod pathway (Schmid et al., 2003). Consistent with this, Schmid et al. (2003) reported that the expression of miR172a-2 was dependent on day-length, $C O$ and FT (Fig. 1). In contrast, Aukerman and Sakai (2003), found that miR172 accumulated to elevated levels with increasing plant age, but found that this accumulation was not affected by day-length or mutations in the photoperiod pathway gene, $C O$ (Fig. 1). Transgenic plants expressing 35S::miR172 flowered early, but still showed a response to photoperiod (ie plants flowered earlier in long day conditions than short day conditions). miR172 acts to block the translation, in addition to promoting the cleavage of AP2 mRNA (Aukerman and Sakai, 2003; Chen, 2003, Kasschau et al., 2003; Schwab et al., 2005). miR172 may act in a similar way to regulate TOE1 and TOE2. Careful analysis by Schwab et al. (2005) revealed that over-expression of mir172a resulted in reduced steady state levels of TOE2 mRNA, but while steady state levels of TOE1 and AP2 mRNA were unchanged, evidence of cleavage of TOE1, TOE2 and AP2 was clear. This discrepancy can be explained by feedback regulation AP2, for example, can directly or indirectly represses its own transcription and this may be true of related factors, like TOE1.

A function in flowering time control has been assigned to $A$. thaliana miR159 (Achard etal., 2004). The hormone gibberellin (GA) promotes the accumulation of miRNA159. Over-expression of miRNA 159 delays flowering specifically in short day conditions. This late flowering phenotype correlates with a decrease in the level of the mRNAs of the transcription factor MYB33 and the floral pathway integrator, $L F Y$ (Fig. 1). However, the expression of SOC1, a component of the GA-induction of flowering is not affected. MYB33 is a direct target of miR159: the MYB33 mRNA is cleaved at an miRNA target site. Therefore, miR159 represses flowering in SD conditions by negatively regulating $M Y B 33$. This produces a reduction in the levels of $\angle F Y$ mRNA and a delay in flowering (Fig. 1).

The expression of a group of SQUAMOSA PROMOTER BINDING PROTEIN LIKE (SPL) genes, in particular SPL3, SPL4 and $S P L 5$ is up-regulated by flowering and dependent on $C O$ and $F T$ (Schmid et al., 2003). This indicates that these genes may be regulators of flowering time. Consistent with this, over-expression of $S P L 3$ had previously been shown to accelerate flowering (Cardon et al., 1997). SPL3, SPL4 and SPL5, have been identified as candidate targets of miRNAs (Rhoades etal., 2002; Kasschau etal., 2003). This hypothesis has recently been tested by Schwab et al. (2005) who demonstrated that over-expression of 35S::mir156b caused late flowering and downregulated the expression of $S P L$ genes with mir156 target sites. Therefore a role for miRNAs in controlling flowering time also extends to the regulation of $S P L$ genes.

\section{Conclusions}

Considerable progress has recently been made in identifying and understanding the genes and molecular processes that control flowering time. This has been achieved through the use of $A$. thaliana as a model system. The discoveries highlight the important role that RNA processing and post-transcriptional regulators play in the floral transition. This is especially significant in the case of the autonomous pathway which includes three RNA-binding proteins FCA, FPA and FLK and a polyadenylation factor, FY. FCA and FY function as a complex that controls FCA expression post-transcriptionally ultimately by alternative polyadenylation. The discoveries made in the control of the expression of the floral identity gene, $A G$, reveal similarities between $F C A$ and $A G$ regulation. This might help us to understand how the RNA processing factors of the autonomous pathway control the expression of the floral repressor $F L C$, the final target of this pathway. However, there is no evidence yet that $F L C$ expression is post-transcriptionally regulated (although it has been described that $F L C$ pre-mRNA is alternatively spliced).

Recent discoveries have been made in the field of RNA metabolism with the identification of miRNAs as key regulators of development in animals and plants. The number of miRNAs identified and their potential target genes continues to increase. Given this and the high proportion of genes encoding RNA-binding proteins in the $A$. thaliana genome we can speculate that in the near future the use of forward and reverse genetics approaches will identify new genes encoding RNA regulators of flowering time in $A$. thaliana. The completion of the genomic sequence of other plant species will help us discover if they function in a similar way in other plants too.

\section{Acknowledgements}

$S C R /$ is supported by grant-in-aid from the Scottish Executive Environment and Rural Affairs Department.

\section{References}

ACHARD, P., HERR, A., BAULCOMBE, D.C. and HARBERD, N.P. (2004). Modulation of floral development by a gibberellin-regulated microRNA. Development 131: 3357-3365.

AMASINO, R. (2004). Vernalization, competence and the epigenetic memory of winter. Plant Cell 16: 2553-2559.

AUKERMAN, M.J. and SAKAI, H. (2003). Regulation of flowering time and floral organ 
identity by a microRNA and its APETALA2-Like target genes. Plant Cel/ 15:27302741

AUSIN, I., ALONSO-BLANCO, C., JARILLO, J.A., RUIZ-GARCIA, L. and MARTINEZZAPATER, J.M. (2004). Regulation of flowering time by FVE, a retinoblastomaassociated protein. Nat. Genet. 36: 162-166.

BARTEL, D.P. (2004). MicroRNAs: genomics, biogenesis, mechanism and function Cell 116: 281-297.

BASTOW, R., MYLNE, J.S., LISTER, C., LIPPMAN, Z., MARTIENSSEN, R.A. and DEAN, C. (2004). Vernalization requires epigenetic silencing of $F L C$ by histone methylation. Nature 427: 164-167.

BEZERRA, I.C., MICHAELS, S., SCHOMBURG, F.M. and AMSINO, R. (2004). Lesions in the mRNA cap-binding gene ABA HYPERSENTITIVE 1 suppresses FRIGIDA -mediated delayed flowering in Arabidopsis thaliana. Plant J. 40: 112119.

BOSS, P.K., BASTOW, R.M., MYLNE, J.S. and DEAN, C. (2004). Multiple pathways in the decision to flower: enabling, promoting and resetting. Plant Cell 16 Suppl:S18-31.

CAICEDO, A.L., STINCHCOMBE, J.R., OLSEN, K.M., SCHMITT, J. and PURUGGANAN, M.D. (2004). Epistatic interaction between Arabidopsis thaliana $F R /$ and $F L C$ flowering time genes generates a latitudinal cline in a life history trait. Proc. Natl. Acad. Sci. USA 101: 15670-15675.

CARDON, G.H., HOHMANN, S., NETTESHEIM, K., SAEDLER, H. and HUIJSER, P. (1997). Functional analysis of the Arabidopsis thaliana SBP-box gene SPL3: a novel gene involved in the floral transition. Plant J. 12: 367-377.

CHEN, X. (2003). A microRNA as a translational repressor of APETALA2 in Arabidopsis thaliana flower development. Science 303: 2022-2025.

CHEN, X. and MEYEROWITZ, E.M. (1999). HUA1 and HUA2 are two members of the floral homeotic AGAMOUS pathway. Mol. Cell 3: 349-460.

CHENG, Y., KATO, N., WANG, W., LI, J. and CHEN, X (2003). Two RNA binding proteins, HEN4 and HUA1, act in the processing of AGAMOUS pre-mRNA in Arabidopsis thaliana. Dev. Cell 4: 53-66.

CRESS, W.D. and SETO, E. (2000). Histone deacetylases, transcriptional control and cancer. J. Cell Physiol. 184: 1-16.

DOYLE, M.R., BIZZELL, C.M., KELLER, M.R., MICHAELS, S.D., SONG, J., NOH, Y.S. and AMASINO, R.M. (2005). HUA2 is required for the expression of floral repressors in Arabidopsis thaliana. Plant J. 41: 376-385.

DUBNAU, J. and STRUHL, G. (1996). RNA recognition and translational regulation by a homeodomain protein. Nature 379: 694-699.

DUGAS, D.V. and BARTEL, B. (2004). MicroRNA regulation of gene expression in plants. Curr. Opin. Plant Biol. 7: 512-520.

EMERY, J.F., FLOYD, S.K., ALVAREZ, J,M ESHED, Y., HAWKER, N.P., IZHAKI, A., BAUM, S.F. and BOWMAN, J.L. (2003). Radial patterning of Arabidopsis thaliana shoots by class III HD-ZIP and KANADI genes. Curr. Biol. 13: 1768-1774.

GAZZANI, S., GENDALL, A.R., LISTER, C. and DEAN, C. (2003). Analysis of the molecular basis of flowering time variation in Arabidopsis thaliana accessions. Plant Physiol. 132: 1107-1114.

GENDALL, A.R., LEVY, Y.Y., WILSON, A. and DEAN, C. (2001) The VERNALIZATION 2 gene mediates the epigenetic regulation of vernalization in Arabidopsis thaliana. Cell 107: 525-535.

GOODRICH, J., PUANGSOMLEE, P., MARTIN, M., LONG, D., MEYEROWITZ, E.M. and COUPLAND, G. (1997). A Polycomb-group gene regulates homeotic gene expression in Arabidopsis thaliana. Nature 386: 44-51.

HAMILTON, A.J. and BAULCOMBE, D.C. (1999). A novel species of small antisense RNA in post-transcriptional gene silencing. Science 286: 950-952.

HARTMANN, U., HOHMANN, S., NETTESHEIM, K., WISMAN, E., SAEDLER, H. and HUIJSER, P. (2000). Molecular cloning of SVP: a negative regulator of the floral transition in Arabidopsis. Plant J. 21: 351-360.

HE, Y., MICHAELS, S.D. and AMASINO, R.M. (2003). Regulation of flowering time by histone acetylation in Arabidopsis thaliana. Science 302: 1751-1754.

HE, Y., DOYLE, M.R. and AMASINO, R.M. (2004). PAF1-complex-mediated histone methylation of FLOWERING LOCUSC chromatin is required for the vernalizationresponsive, winter-annual habit in Arabidopsis thaliana. Genes Dev. 302: 17511754

HENDERSON, I.R. and DEAN, C. (2004). Control of Arabidopsis thaliana flowering: the chill before the bloom. Development 131: 3829-3838.
HONG, R.L., HAMAGUCHI, L., BUSCH, M.A. and WEIGEL, D. (2003). Regulatory elements of the floral homeotic gene AGAMOUS identified by phylogenetic footprinting and shadowing. Plant Cell 15: 1296-1309.

HUGOUVIEUX, V., KWAK, J.M. and SCHROEDER, J.I. (2002). An mRNA cap binding protein, $\mathrm{ABH} 1$, modulates early abscisic acid signal transduction in Arabidopsis thaliana. Cell 106: 477-487.

JOHANSON, U., WEST, J., LISTER, C., MICHAELS, S., AMASINO, R. and DEAN, C. (2000) Molecular analysis of $F R / G I D A$, a major determinant of natural variation in Arabidopsis thaliana flowering time. Science 290: 344-347.

KASSCHAU, K.D., XIE, Z., ALLEN, E., LLAVE, C., CHAPMAN, E.J., KRIZAN, K.A. and CARRINGTON, J.C. (2003). P1/HC-Pro, a viral suppressor of RNA silencing, interferes with Arabidopsis thaliana development and miRNA unction. Dev. Cell 4: 205-217.

KOMURO, A., SAEKI, M. and KATO, S. (1999). Npw38, a novel nuclear protein possessing a WW domain capable of activating basal transcription. Nucleic Acids Res. 27: 1957-1965.

KOORNNEEF, M., ALONSO-BLANCO, C., BLANKESTIJN-DE VRIES, H., HANHART, C. J. and PEETERS, A. J. M. (1998). Genetic interactions among late flowering mutants of Arabidopsis thaliana. Genetics 148: 885-892.

LAGOS-QUINTANA, M., RAUHUT, R., LENDECKEL, W. and TUSCHL, T. (2001). Identification of novel genes coding for small expressed RNAs. Science $294: 853$ 858.

LAU, N.C., LIM, L.P., WEINSTEIN, E.G. and BARTEL, D.P. (2001). An abundant class of tiny RNAs with probable regulatory roles in Caenorhabditis elegans. Science 294: 858-862

LEE, I., AUKERMAN, M.J., GORE, S.L., LOHMAN, K.N., MICHAELS, S.D., WEAVER, L.M., JOHN, M.C., FELDMANN, K.A. and AMASINO, R.M. (1994). Isolation of $\angle U M I N I D E P E N D E N S$ : a gene involved in the control of flowering time in Arabidopsis thaliana. Plant Cell 6: 75-83.

LEE, R.C. and AMBROS V. (2001). An extensive class of small RNAs in Caenorhabditis elegans. Science 294: 862-864

LEWIS, J.D., IZAURRALDE, E., JARMOLOWSKI, A., MCGUIGAN, C. and MATTAJ, I.W. (1996). A nuclear cap-binding complex facilitates association of U1 snRNP with the cap-proximal 5' splice site. Genes Dev. 10: 1683-1698.

LI, J., JIA, D. and CHEN, X. (2001). HUA1, a regulator of stamen and carpel identities in Arabidopsis thaliana, codes for a nuclear RNA binding protein. Plant Cell 13: 2269-2281.

LIM, M.H., KIM, J., KIM, Y.S., CHUNG, K.S., SEO, Y.H., LEE, I., KIM, J., HONG, C.B., KIM, H.J. and PARK, C.M. (2004). A New Arabidopsis thaliana Gene, FLK Encodes an RNA Binding Protein with K Homology Motifs and Regulates Flowering Time via FLOWERING LOCUS C. Plant Cel/ 101: 12759-12764.

LIU, J., HE, Y., AMASINO, R. and CHEN, X. (2004). siRNAs targeting an intronic transposon in the regulation of natural flowering behaviour in Arabidopsis thaliana. Genes Dev. 18: 2873-2878.

LORKOVIC, Z. J. and BARTA, A. (2002). Genome analysis: RNA recognition motif (RRM) and $\mathrm{K}$ homology $(\mathrm{KH})$ domain RNA-binding proteins from the flowering plant Arabidopsis thaliana. Nucleic Acids Res. 30: 623-635.

MACKNIGHT, R., BANCROFT, I., PAGE, T., LISTER, C., SCHMIDT, R., LOVE, K., WESTPHAL, L., MURPHY, G., SHERSON, S., COBBETT, C. and DEAN, C. (1997). FCA, a gene controlling flowering time in Arabidopsis thaliana, encodes a protein containing RNA-binding domains. Cel/ 89: 737-745.

MACKNIGHT, R., DUROUX, M., LAURIE, R., DIJKWEL, P., SIMPSON, G. and DEAN, C. (2002). Functional significance of the alternative transcript processing of the Arabidopsis thaliana floral promoter FCA. Plant Cell 14: 877-888.

METTE, M.F., VAN DER WINDEN, J., MATZKE, M. and MATZKE, A.J. (2002). Short RNAs can identify new candidate transposable element families in Arabidopsis thaliana. Plant Physiol. 130: 6-9.

MICHAELS, S. D. and AMASINO, R. M. (1999). FLOWERING LOCUSC encodes a novel MADS domain protein that acts as a repressor of flowering. Plant Cel/ 11: 949-956.

MICHAELS, S,D., HE, Y., SCORTECCI, K.C. and AMASINO, R.M. (2003). Attenuation of FLOWERING LOCUS $\mathrm{C}$ activity as a mechanism for the evolution of summer-annual flowering behavior in Arabidopsis thaliana. Proc. Natl. Acad. Sci. USA 100: 10102-10107.

MICHAELS, S.D., BEZERRA, I.C. and AMASINO, R.M. (2004). FRIGIDA -related genes are required for the winter-annual habit in Arabidopsis thaliana. Proc. Natl. 
Acad. Sci. USA 101: 3281-3285.

MOURADOV, A, CREMER, F. and COUPLAND, G. (2002). Control of flowering time: interacting pathways as a basis for diversity. Plant Cell 14 Suppl:S111-30.

MUELLER, C.L., PORTER, S.E., HOFFMAN, M.G. and JAEHNING, J.A. (2004). The Paf1 complex has functions independent of actively transcribing RNA polymerase II. Mol. Cell 14: 447-456.

MURTAS, G., REEVES, P.H., FU, Y.F., BANCROFT, I., DEAN, C. and COUPLAND, G. (2003). A nuclear protease required for flowering-time regulation in Arabidopsis thaliana reduces the abundance of SMALL UBIQUITIN-RELATED MODIFIER conjugates. Plant Cell 15: 2308-2319.

NOH, Y.S. and AMASINO, R.M. (2003). PIE1, an ISWI family gene, is required for FLC activation and floral repression in Arabidopsis thaliana. Plant Cel/ 15: 1671-1682.

NOH, Y.S., BIZZELL, C.M., NOH, B., SCHOMBURG, F.M. and AMASINO, R.M. (2004a). EARL Y FLOWERING5 acts as a floral repressor in Arabidopsis thaliana. Plant J. 38: 664-672.

NOH, B., LEE, S.H., KIM, H.J., YI, G., SHIN, E.A., LEE, M., JUNG, K.J., DOYLE, M.R., AMASINO, R.M. and NOH, Y.S. (2004b). Divergent roles of a pair of homologous jumonji/zinc-finger-class transcription factor proteins in the regulation of Arabidopsis thaliana flowering time. Plant Cell 16: 2601-2613.

OH, S., ZHANG, H., LUDWIG, P. and VAN NOCKER, S. (2004). A Mechanism Related to the Yeast Transcriptional Regulator Paf1c Is Required for Expression of the Arabidopsis thaliana FLC/MAF MADS Box Gene Family. Plant Cell 16: 2940-2953.

OHNACKER, M., BARABINO, S.M., PREKER, P.J. and KELLER, W. (2000). The WDrepeat protein pfs $2 p$ bridges two essential factors within the yeast pre-mRNA 3'end-processing complex. EMBO J. 19: 37-47.

PALATNIK, J.F., ALLEN, E., WU, X., SCHOMMER, C., SCHWAB, R., CARRINGTON, J.C. and WEIGEL, D. (2003). Control of leaf morphogenesis by microRNAs. Nature 425: 257-263.

PARK, W., LI, J., SONG, R., MESSING, J. and CHEN, X. (2002).CARPEL FACTORY, a Dicer homolog and HEN1, a novel protein, act in microRNA metabolism in Arabidopsis thaliana. Curr. Biol. 12: 1484-1495.

PUTTERILL, J., LAURIE, R. and MACKNIGHT, R. (2004). It's time to flower: the genetic control of flowering time. Bioessays 26: 363-373.

QUESADA, V., MACKNIGHT, R., DEAN, C. and SIMPSON, G.G. (2003). Autoregulation of $F C A$ pre-mRNA processing controls Arabidopsis thaliana flowering time. EMBO J. 22: 3142-3152.

RATCLIFFE, O.J., KUMIMOTO, R.W., WONG, B.J. and RIECHMANN, J.L. (2003) Analysis of the Arabidopsis MADS AFFECTING FLOWERING gene family: MAF2 prevents vernalization by short periods of cold. Plant Cel/ 15: 1159-1169.

REEVES, P.H., MURTAS, G., DASH, S. and COUPLAND, G. (2002). early in short days 4, a mutation in Arabidopsis thaliana that causes early flowering and reduces the mRNA abundance of the floral repressor FLC. Development 129: 5349-5361.

REINHART, B.J., SLACK, F.J., BASSON, M., PASQUINELLI, A.E., BETTINGER, J.C., ROUGVIE, A.E., HORVITZ, H.R. and RUVKUN, G. (2000). The 21-nucleotide let-7 RNA regulates developmental timing in Caenorhabditis elegans. Nature 403: 901-906.

REINHART, B.J., WEINSTEIN, E.G., RHOADES, M.W., BARTEL, B. and BARTEL, D.P. (2002). MicroRNAs in plants. Genes Dev. 16: 1616-1626.

RHOADES, M., REINHART, B., LIM, L., BURGE, C., BARTEL B. and BARTEL, D. (2002). Prediction of plant microRNA targets. Cell 110: 513-520.

RIVERA-POMAR, R., NIESSING, D., SCHMIDT-OTT, U., GEHRING, W.J. and JACKLE, H. (1996). RNA binding and translational suppression by bicoid. Nature 379: 746-749.

SANTOS-ROSA, H., SCHNEIDER, R., BANNISTER, A.J., SHERRIFF, J.,
BERNSTEIN, B.E., EMRE, N.C., SCHREIBER, S.L., MELLOR, J. and KOUZARIDES, T. (2002). Active genes are tri-methylated at K4 of histone H3. Nature 419: 407-411.

SCHMID, M., UHLENHAUT, N.H., GODARD, F., DEMAR, M., BRESSAN, R., WEIGEL, D. and LOHMANN, J.U. (2003) Dissection of floral induction pathways using global expression analysis. Development 130: 6001-6012.

SCHOMBURG, F. M., PATTON, D. A., MEINKE, D. W. and AMASINO, R. M. (2001). FPA, a gene involved in floral induction in Arabidopsis thaliana, encodes a protein containing RNA-recognition motifs. Plant Cell 13: 1427-1436.

SCHWAB, R., PALATNIK, J.F., RIESTER, M., SCHOMMER, C., SCHMID, M. and WEIGEL, D. (2005). Specific effects of microARNs on the plant transcriptome Dev. Cell 8: 517-527.

SCORTECCI, K.C., MICHAELS, S.D. and AMASINO, R.M. (2001). Identification of a MADS-box gene, FLOWERING LOCUS M, that represses flowering. Plant J. 26: 229-236.

SHELdON, C.C., BURN, J., E., PEREZ, P.P., METZGER, J., EDWARDS, J.A PEACOCK, W.J. and DENNIS, E.S. (1999) The FLFMADS box gene: a repressor of flowering in Arabidopsis thaliana regulated by vernalization and methylation. Plant Cell 11: 445-458.

SHELDON, C.C., CONN, A.B., DENNIS, E.S. and PEACOCK, W.J. (2002). Different regulatory regions are required for the vernalization-induced repression of $F L O W$ ERINGLOCUSC and for the epigenetic maintenance of repression. Plant Cel/ 14: 2527-2537.

SIMPSON, G.G. and DEAN, C. (2002). Arabidopsis thaliana, the Rosetta stone of flowering time? Science 296: 285-289.

SIMPSON, G.G., DIJKWEL, P.P., QUESADA, V., HENDERSON, I. and DEAN, C. (2003). FY is an RNA 3' end-processing factor that interacts with FCA to control the Arabidopsis thaliana floral transition. Cell 113: 777-787.

SIMPSON, G.G. (2004). The autonomous pathway: epigenetic and post-transcriptional gene regulation in the control of Arabidopsis thaliana flowering time. Curr Opin. Plant Biol. 7: 570-574.

SUDOL, M. and HUNTER, T. (2000). NeW wrinkles for an old domain. Cell 103: 10011004.

SUNG, S. AND AMASINO, R.M. (2004). Vernalization in Arabidopsis thaliana i s mediated by the PHD finger protein VIN3. Nature 427: 159-164.

TIAN, L., FONG, M.P., WANG, J.J., WEI, N.E., JIANG, H., DOERGE, R.W. and CHEN, Z.J. (2005). Reversible histone acetylation and deacetylation mediate genome-wide, promoter-dependent and locus-specific changes in gene expression during plant development. Genetics 169: 337-345.

WESTERN, T.I., CHENG, Y., LIU, J. and CHEN, X. (2002). HUA ENHANCER2, a putative DexH-box RNA helicase, maintains homeotic $B$ and $\mathrm{C}$ gene expression in Arabidopsis thaliana. Development 129: 1569-1581.

XIE, Z., KASSCHAU, K.D. and CARRINGTON, J.C. (2003). Negative feedback regulation of Dicer-Like1 in Arabidopsis thaliana by microRNA-guided mRNA degradation. Curr. Biol. 13: 784-789.

YANG, X.J. and SETO, E. (2003). Collaborative spirit of histone deacetylases in regulating chromatin structure and gene expression. Curr. Opin. Genet. Dev. 13: 143-153.

YANOFSKY, M.F., MA, H., BOWMAN, J.L., DREWS, G.N., FELDMANN, K.A. and MEYEROWITZ, E.M. (1990). The protein encoded by the Arabidopsis thaliana homeotic gene agamous resembles transcription factors Nature 346: 35-39.

YEKTA, S., SHIH, I.H. and BARTEL, D.P. (2004). MicroRNA-directed cleavage of the HOXB8 mRNA. Sicence 304: 594-596.

ZHANG, $\mathrm{H}$. and VAN NOCKER, S. (2002). The VERNALIZATION INDEPENDENCE 4 gene encodes a novel regulator of FLOWERINGLOCUS CPlantJ.31:663-673. 